\title{
Long-term selection experiment with Afrikaner cattle 4. Cow fertility and calf survival
}

\author{
L.M. Beffa ${ }^{1,2,3}$, J.B. van Wyk ${ }^{1 \#}$ and G.J. Erasmus ${ }^{1}$ \\ ${ }^{1}$ University of the Free State, P.O. Box 339, Bloemfontein 9300, South Africa \\ ${ }^{2}$ Matopos Research Station, P. Bag K5137, Bulawayo, Zimbabwe
}

\begin{abstract}
A selection and line $\mathrm{x}$ environment interaction study with grade Afrikaner cattle was established in 1956 at the Matopos Research Station, Zimbabwe. Two selection lines of 100 cows each were reared in different management environments. The non-supplemented (NS) line relied on the range throughout the year and was mated to calve with the onset of the rains (December to February). The supplemented (S) line was offered protein-rich supplements during the dry season and mated to calve prior to the onset of the rains (October to December). In 1976, after approximately two generations of selection, lines were sub-divided into 75 cows each, where one sub-line remained within each environment as a control; the remaining sublines were interchanged between environments. Bulls were selected on weaning weight within control lines, while replacement heifers were selected on weight at mating within sub-line. Data recorded over six generations of selection (40 years) were analyzed. The average incidence of calving success (the presence or absence of a calf) was $68 \%$. Heritability and repeatability (in parenthesis) estimates for calving success and calving date were $0.08 \pm 0.02(0.10 \pm 0.02)$ and $0.09 \pm 0.02(0.17 \pm 0.02)$, respectively. Favourable genetic trends were shown $(-0.8 \pm 0.09$ days/generation for calving date). Correlation estimates of sires' EBV between measures of fertility and growth were all unfavourable. A significant interaction was manifested for calving success and was due to the markedly poorer performance (10 percentage units) of the $\mathrm{S}$ line cows in the NS environment. The interaction serves to reinforce the commonly held principle that cattle, and in particular breeding cows, be reared in a similar environment in which selection takes place advocating antagonistic selection (upwards selection in a poor environment). Calf losses within the first $24 \mathrm{~h}$ of birth and pre-weaning were $3.8 \%$ and $8 \%$, with heritability estimates of $0.15 \pm 0.07$ and $0.07 \pm 0.03$, respectively. It is recommended that fertility and calf survival be included in routine breed evaluations. There is a need to implement data collection strategies to ensure that all calving activities are comprehensively recorded.
\end{abstract}

Keywords: Sanga, sub-tropics, genetic parameters, genetic correlation, genotype x environment interaction

${ }^{\#}$ Corresponding author. E-mail: vanwykjb.sci@ufs.ac.za

${ }^{3}$ Current address. Livestock Identification Trust, P.O. Box BE 209, Belvedere, Harare, Zimbabwe

\section{Introduction}

Fertility and survival are of vital importance to all livestock enterprises and should be included in beef cattle breeding programmes (Newman et al., 1992; Ponzoni, 1992; Goyache et al., 2003; Kadarmideen \& Wegmann, 2003; Prayaga, 2004). However, the genetic analysis of such traits, particularly in range beef cattle, has received relatively little attention as compared to production traits as they are difficult to measure and interpret (Donoghue et al., 2004a; Prayaga, 2004). As a result, it is generally considered that selection has limited potential to improve fertility and calf survival in beef cattle (Patterson et al., 1987; Cubas et al., 1991; Davis et al., 1993; Morris et al., 2000; Gutiérrez et al., 2002; Rust \& Groeneveld, 2002; Prayaga, 2004). Heritability estimates for fertility traits have been found to be considerably higher in heifers than in cows (Koots et al., 1994; Rust \& Groeneveld, 2001) and have been ascribed to the culling of infertile cows, thereby reducing the genetic variance (Johnson \& Notter, 1987). In general higher heritabilities for days to calving rather than calving success have been reported (Johnston et al., 2001; Rust \& Groeneveld, 2001; Donoghue et al., 2004b). Recent studies have, however, reported relatively high estimates for pregnancy rate in heifers (0.14 to 0.37) (Evans et al., 1999; Doyle et al., 2000; Dias et al., 2002), which have been attributed to the adoption of adequate statistical methods to handle categorical traits.

Recording of survival traits in extensively managed range beef cattle is problematic: survival data are often derived from presence or absence of live-weights at certain ages/weights in the course of the animals' 
life, with survival from birth to weaning being commonly reported. Perinatal survival (within $24-48 \mathrm{~h}$ of birth) is of major concern in both the beef and dairy industry. Patterson et al. (1987) reported that of the total losses up to weaning in beef cattle, $67 \%$ were recorded within the first $48 \mathrm{~h}$, while Prayaga (2004) found that $80 \%$ of pre-weaning mortalities had occurred within the first week of birth, $50 \%$ of which was due to abortions. In both the beef and dairy industry, losses have been reported to be twice as high in heifers than in cows (Harbers et al., 2000; Meyer et al., 2001; Goyache et al., 2003). Perinatal heritability estimates for survival traits are typically low, but are reported to be twice as high in beef ( 0.15 in heifers and 0.10 in cows) (Koots et al., 1994) compared to dairy cattle (Luo et al., 1999; Harbers et al., 2000). Studies indicate that stillbirths in heifers and in cows are different traits (Philipsson, 1996; Harbers et al., 2000). Philipsson (1996) suggested the biological reason for the difference may be due to calf size relative to cow size. Late mortality, occurring from the perinatal period to weaning is generally considered to be caused by environmental factors such as sporadic disease or accidental losses (Bellows et al., 1987; Patterson et al., 1987). Consequently genetic studies on late calf mortality are scarce (Goyache et al., 2003; Tarrés et al., 2005).

The objectives of this study were to quantify the genetic and environmental factors affecting cow fertility and calf survival to weaning and to determine the presence and importance of a genotype $\mathrm{x}$ environment interaction.

\section{Materials and Methods}

A more detailed description of the animals, environment and experimental protocol of the two lines (supplemented (S) and non-supplemented (NS)) is given in a companion paper (Beffa et al., 2009a). Two lines of 100 grade Afrikaner cows each were established in 1956 and subjected to different nutritional and management regimes. The non-supplemented (NS) line cows were mated to calve two months later than those in the $\mathrm{S}$ line. A fixed mating season of 90 days and four single-sired herds of 25 cows each were used within each line. Selection for weight within line, to establish lines adapted to their respective environments, was based on weight at weaning for bulls and weight prior to mating (three years) for replacement heifers. In 1976 the number of breeding females in each line was increased to 150 and two equal sub-lines were created. One sub-line remained within each environment as a control (S/S and NS/NS, leading symbol denotes selection line, trailing symbol environment post-crossover). The remaining sub-lines were interchanged between environments (S/NS and NS/S). The mating season was decreased to 65 days for the 1977 to 1982 matings, but subsequently reverted to 90 days. Bulls were selected within the control sub-lines and were used within line across environments. Cows were mated in five single-sire herds of 15 cows each. The data analyzed in this study were collected over 40 years (1958 to 1997).

Calving success (CS) was defined as the presence (1) or absence (0) of a calf, where the presence of a calf included abortions at term ( $>8$ months) and stillbirths. As the mating season starting date was not known with certainty (particularly for the pre-crossover period), calving date (CD) as opposed to 'days to calving' was analyzed. Calving date was taken as the number of days from a base date of $1^{\text {st }}$ September (approximately three weeks before the start of the calving season). Non-calvers were assigned a penalty date equal to the last day of calving within year-environment cohort plus 21 days (Johnston \& Bunter, 1996). The constant is equal to one oestrous cycle and suggests that open cows would have calved given an extra cycle with the bull. In this study, however, with daily inspection of cows, only observations up to $24 \mathrm{~h}$ from birth were available. Thus for all cows calving, abortions at term ( $>8$ months) and stillbirths (STIL), analyzed as a trait of the cow, were defined as the presence of a live (1: birth weight present) or dead (0: calving date but no birth weight) calf. Calf survival between birth and 205 days (SURV) was analyzed as a trait of either the cow or the calf and was defined as alive (1) or dead (0) at 205 days.

Data for heifers and cows were combined for two primary reasons. The age at first mating of heifers in the pre-crossover phase was at three years compared with two years in the post-crossover phase and the small number of observations in the line-year-environment cohorts (ranging from 4 to 16 for number of matings in the post-crossover phase) resulted in very few observations per sire (one third of the total of 193 sires with less than five observations on heifer matings). Fixed effects considered for all traits were year of mating, line, environment, age of dam and previous lactation status (PLS: heifer, suckling or not suckling a calf in the previous season). After perusal of means for the various dam age groups the following categories were assigned: $3,4,5$ to 7,8 to 10 , and $>10$ years. The effects of dam age and PLS were concatenated to 
account for confounding of heifer age and PLS, yielding nine classes. For the fertility traits, the effects of year, line and environment were concatenated to account for interaction with years.

For the survival traits, year-environment contemporary groups were defined and line was fitted as a separate effect. Data were discarded where contemporary groups showed no variation (i.e. no losses). Furthermore, for STIL, it was obvious that up to and including 1982 no attempt had been made to capture all calving activities (i.e. abortions and stillbirths) and hence only post-1982 data were considered. Age of dam categories for $>10$ years were recoded to $>8$ years to account for lack of variation in the $>10$ years and previously non-suckling group. The sex of calf was not known with the indirect method of determination of calf loss at birth for STIL, and hence could not be used as a fixed effect in the analyses. Calving date, calf sex (male or female) and calf birth weight were taken into account for SURV. Calving date and birth weight were treated as linear and quadratic covariates, deviated from their means, divided by their standard deviations. Random effects of the animal (cow or calf), maternal genetic, service sire, and repeated measurements on either the cow or dam were considered for all the traits. Records on foundation cows were discarded in the analyses of traits of the cow, as well as records for the first progeny crop of heifers mated in 1961 due to confounding of age of dam, PLS and year of mating. Records were also discarded where there were less than five observations per sire.

The binomially distributed traits (CS, STIL and SURV) were analyzed with the ASREML programme using a univariate animal model with a logit link function to link the binomially distributed data to the normal distribution (Gilmour et al., 2002). The F ratio was used to determine the significance of the fixed effects, after which significance of the addition of random effects were tested individually. The $\log$ likelihood ratio test is not a good indicator of whether to include or exclude a random effect with a logit model. Hence the REML estimate of variance component divided by the square root of the diagonal element of the inverse of the average information matrix (Component/SE) (Gilmour et al., 2002) and standard error of the variance ratio were adopted to give an indication of the significance of a random component, where a Component/SE ratio of less than 1 or standard error of more than twice the variance ratio indicated nonsignificant contribution to the model fit. The ASREML algorithm was also utilized to analyze both CS and $\mathrm{CD}$, assuming these traits were normally distributed traits (linear approach). The analysis of the CS was undertaken to determine the effect of ignoring the binomial distribution of the trait. The general model used in matrix notation was:

$$
\mathrm{Y}=\mathrm{X} \beta+\mathrm{Z}_{1} \mathrm{a}+\mathrm{Z}_{2} \mathrm{~m}+\mathrm{Z}_{3} \mathrm{c}+\mathrm{Z}_{4} \mathrm{~s}+\varepsilon
$$

where: $\mathrm{Y}$ is the vector of observations;

$\beta$ is the vector of fixed effects (line-year-environment with 114 levels and age of dam-previous

lactation status with nine levels);

$\mathrm{X}$ is the incidence matrix that associates $\beta$ with $\mathrm{Y}$;

a is the vector of breeding values for direct genetic effects;

$\mathrm{m}$ is the vector of breeding values for maternal genetic effects;

$\mathrm{c}$ is the vector of permanent environmental effects due to cow;

$\mathrm{s}$ is the vector of effects due to service sire;

$\mathrm{Z}_{1}, \mathrm{Z}_{2}, \mathrm{Z}_{3}$ and $\mathrm{Z}_{4}$ are the incidence matrices that associate $\mathrm{a}, \mathrm{m}, \mathrm{c}$ and $\mathrm{s}$ with $\mathrm{Y}$ and $\varepsilon$ is the vector of residual effects.

Furthermore, with A, the numerator relationship matrix between animals, $\mathrm{I}_{\mathrm{n}}$, an identity matrix with order $\mathrm{n}$, the number of dams, and I, an identity matrix with order of the number of records. The (co)variance structure of random effects can be described as: $\mathrm{V}(\mathrm{a})=\sigma_{\mathrm{a}}^{2} \mathrm{~A}, \mathrm{~V}(\mathrm{~m})=\sigma_{\mathrm{m}}^{2} \mathrm{~A}, \mathrm{~V}(\mathrm{c})=\sigma_{\mathrm{c}}{ }_{\mathrm{c}} \mathrm{I}_{\mathrm{n}}, \mathrm{V}(\varepsilon)=\sigma_{\varepsilon}^{2} \mathrm{I}$, where $\sigma_{a}^{2}$ is the direct genetic variance; $\sigma_{m}^{2}$ is the maternal genetic variance; $\sigma_{c}^{2}$ is the maternal permanent environment variance; $\sigma_{\mathrm{e}}^{2}$ is the residual variance and $\sigma_{\mathrm{am}}$ is the genetic covariance between direct and maternal effects.

Calving success breeding values (tbv) were derived from the back transformation of the animal solutions on the underlying scale, bv, to the probability scale, tbv, by the formula: tbv $=1 /\left(1+\mathrm{e}^{-\mathrm{bv}}\right)(\mathrm{Neter}$ et al., 1983). Genetic trends were determined from the regression of individual's CD breeding values and CS breeding values (tbv's) against generation number. Correlations of breeding values for sires with more than 
10 daughters with mating records were used to determine the relation between CS analyzed with nonlinear procedures and $\mathrm{CD}$ analyzed with linear procedures. In addition, the genetic correlation between $\mathrm{CD}$ and CS was estimated in a bivariate analysis using the MTDFREML algorithm following procedures outlined by Boldman et al. (1995). The ASREML programme with a logit link was used for all binomially distributed traits to test for the presence of a line $\mathrm{x}$ environment interaction. For CS, the post-crossover data set after the mating season had reverted to 90days (1983 to 1997) was used, similarly for STIL, whereas the complete crossover data set (1977 to 1997) was analyzed for the calf survival traits. The random effects found to be of importance in the analyses of the full data sets were included as well as all possible fixed effects: however, effects of year, line and environment were separated and the two way interaction of line $\mathrm{x}$ environment was included. The $\mathrm{F}$ ratio was employed to test for a significant interaction. Considering the full dataset, additional random components of sire $\mathrm{x}$ environment, sire $\mathrm{x}$ year and sire $\mathrm{x}$ year-environment were individually included in the single trait analyses of CD. The difference of minus twice the log likelihoods with $\chi_{05}^{2}$ test with one degree of freedom was used to determine if the addition of a random factor significantly improved the model fit (Meyer \& Hill, 1992).

\section{Results and Discussion}

A summary of the data description after final editing is given in Table 1 . The relatively low incidence for CS of $68 \%$ out of 8862 matings is in accordance with estimates reported in literature (Harwin et al., 1967; Rakha et al., 1971; Trail et al., 1977; Holness et al., 1980; Moyo, 1990) and compares favourably with a value of $61 \%$ for field data for Afrikaner cattle obtained in South Africa for the period 1976 to 1998 (Rust \& Groeneveld, 2002).

Table 1 Incidence and number of records (including censored data) used for analyses of cow fertility and calf survival in a long-term selection experiment in Afrikaner cattle

\begin{tabular}{lcccc}
\hline & Calving & Abortions and & \multicolumn{3}{c}{ Calf loss } \\
\cline { 5 - 5 } & success & stillbirths & Trait of the cow & Trait of the calf \\
\hline Incidence (\%) & & & & \\
Records & 68.1 & 3.8 & 7.9 & 7.9 \\
Cows (records per cow) & 8862 & 3047 & 5726 & 6818 \\
Sires (records per sire) & $1545(5.7)$ & $807(3.8)$ & $1290(4.4)$ & - \\
Dams (records per dam) & $193(45.9)$ & $134(22.7)$ & $171(33.5)$ & $214(31.9)$ \\
Service sires (records per service sire) & $212(41.8)$ & $120(25.4)$ & $209(27.4)$ & $1578(4.3)$ \\
Line-Year-Environment & 114 & - & - & - \\
Year-Environment & - & 30 & 71 & - \\
Dam age-previous lactation status & 9 & 7 & 9 & 90 \\
& & & & \\
\hline
\end{tabular}

A total of 193 sires and 889 dams were represented in the analyses of CS and CD (Table 1). Variance ratios for all random effects were low $(<10 \%$ : Table 2$)$. The direct heritability estimates for CS (nonlinear model) were similar to that of CD. However, repeatability estimates (repeated measurements on the cow) for $\mathrm{CD}$ were higher than those for CS. Service sire contributed to model fit but variance ratios were very low (0.01 - 0.02). Heritability estimates for the analyses of both CS (nonlinear) and CD within heifers (mated to calve at 4 in the pre-crossover or at 3-years of age in the post-crossover phases) and cows were the same as for the combined datasets (not presented); however, estimates of service sire variance were 0.05 for the heifer dataset in both analyses. While the interaction of sire $\mathrm{x}$ year was important $(\mathrm{P}<0.05)$ in the analyses of $\mathrm{CD}$, the interaction did not materially affect the variance ratios (Table 2). 
Table 2 Variance ratios (expressed as a proportion of phenotypic variance) for measures of fertility in Afrikaner cattle

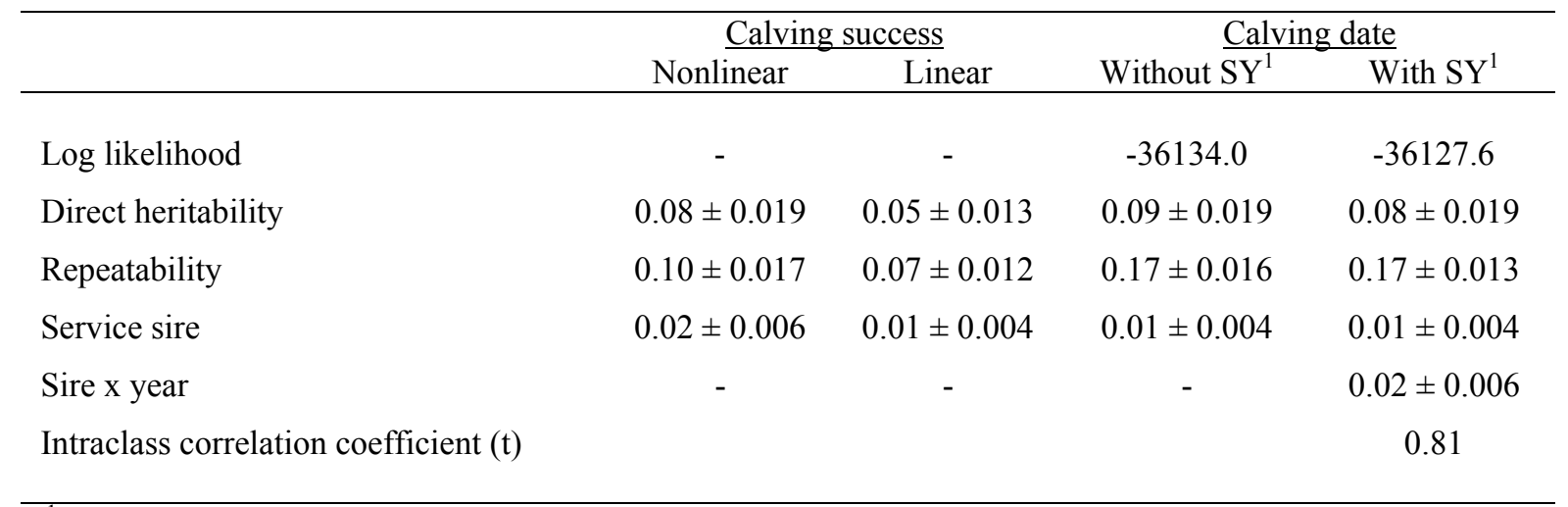

${ }^{1}$ Sire $\mathrm{x}$ year interaction

As expected, a lower estimate of direct heritability was obtained for CS analyzed with a linear model. Transformation of the estimate to the underlying normal scale as proposed by Lush et al. (1948) by the equation, $h_{n}^{2}=h^{2}(1-p) p / z^{2}$, where $h^{2}$ is the heritability on the underlying normal scale, $h^{2}$ is the heritability on the observable binomial scale, $\mathrm{p}$ is the population frequency of the trait and $\mathrm{z}$ is the normal ordinate for $\mathrm{p}$, increased the estimate to 0.09 . The heritability and repeatability estimates for CS and CD in this study concur with more recent literature estimates ( 0.02 to 0.11 and 0.02 to 0.11 for CS; 0.03 to 0.39 and 0.10 to 0.26 for $C D$, respectively) (Rust \& Groeneveld, 2001; Meyer \& Johnston, 2003). In their linear analyses of 209000 records of field data for Afrikaner cattle in South Africa, Rust \& Groeneveld (2002) found no evidence of additive genetic variation for CS, in contrast to the nonlinear analyses of CS in a selected data set (sires used in more than four herds with more than 75 offspring), where a heritability estimate derived from sire variance components of 0.27 was reported.

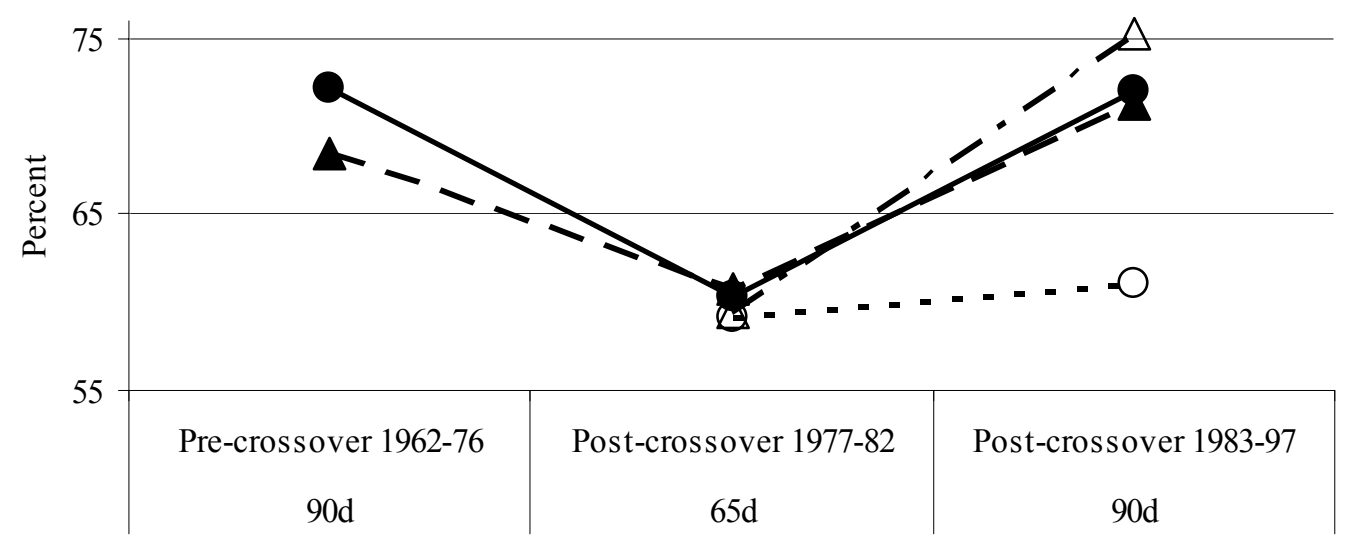

Phase and length of mating season

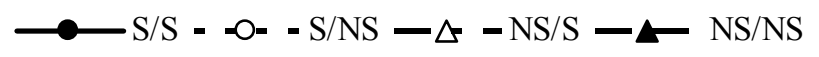

Figure 1 Effect of experimental phase and length of mating season on calving success.

The higher CS of the S line in the pre-crossover phase presumably reflects the very high dry season supplementation regime (Figure 1). All the lines responded adversely to the reduced length of mating season immediately post-crossover and showed an average CS of $60 \%$, which corresponds well with the CS of 56\% reported by Moyo (1990) for Afrikaner cows subjected to a 70-day mating season in a similar environment. 
A classic genotype $\mathrm{x}$ environment interaction was evident $(\mathrm{P}<0.05)$ upon reverting to a 90day mating season with the NS/S line showing the greatest response in CS of 16 percentage units, followed by the S and NS control lines with a 12 and 10 percentage units increase respectively. However, S line cattle reared in the NS environment only responded by two percentage units. While both lines showed superior incidence of CS in the $\mathrm{S}$ environment, suggesting that the $\mathrm{S}$ environment was superior for the expression of the trait, it is difficult to reconcile the large reduction in performance of the S line in the NS environment with the actual difference between environments. The interaction serves to reinforce the commonly held principle that cattle, and in particular breeding cows, be reared in a similar environment in which selection takes place. Jinks \& Connolly (1973), Falconer (1990) and Falconer \& Mackay (1996) reported that in general, upwards selection in a poor environment, termed "antagonistic" selection, is advocated. Antagonistic selection has been found to decrease environmental sensitivity and improve overall selection response.

The average $\mathrm{CD}$ in the NS environment ranged from 51 to 58 days later than the $\mathrm{S}$ environment, despite the fact that cows in the NS environment were joined 65 days later. This was due to different calving patterns (Figure 2), where presumably, a larger proportion of cows in the NS environment would have been gaining weight for several months, and would therefore be more receptive to the bull at the start of their mating season in mid-February, compared with their S counterparts. The effect of assigning a penalty value to non-calvers resulted in marked bimodal distributions.

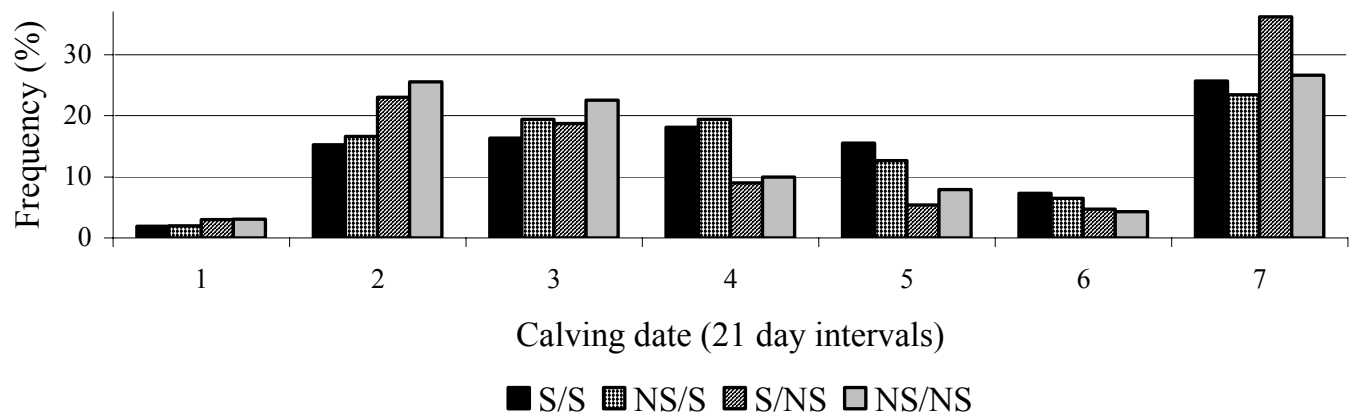

Figure 2 Calving distribution for the post-crossover phase with a 90day mating season.

Age of dam-previous lactation status was the most important fixed effect affecting CS and CD where CS increased with dam age peaking at five to seven years, before declining for dams older than 10 years (Figure 3). The effect of suckling a calf in the previous season was most pronounced for first calvers (fouryear-old cows) of 51 percentage units and was also marked for older cows (24 to 27 percentage units). The performance of heifers was lower than that of 'dry' cows between four to 10 years, while the performance of 'dry' cows greater than 10 years declined by 15 percentage units. Similar effects of PLS were reported by Hetzel et al. (1985). In their report on a selection experiment for pregnancy rate in the tropics, Davis et al. (1993) found a marked effect of PLS of 19 and 39 percentage units on first calvers (3-year-old cows) in the 'Low' and 'High' lines, respectively. Frisch (1989) found that the detrimental effect of PLS increased when CS was low - the latter being described as an indicator of environmental stress. In contrast, Archer et al. (1998) reported 8 percentage units higher pregnancy rates for cows that had calved in the previous year, and while the pregnancy rate of first lactation cows and older cows was lower than that of other age groups, the differences were only 10 percentage units.

Calf losses within the first $24 \mathrm{~h}$ of $3.8 \%$ (Table 1) in this study compares favourably with literature estimates for both beef (3.0 - 4.9\%) (Morris et al., 1992; Goyache et al., 2003) and dairy cattle (5.4 - 7.0\%) (Weller et al., 1998; Harbers et al., 2000; Meyer et al., 2001). Pre-weaning calf loss of $8 \%$ (of calves born alive) was disconcertingly high (Table 1), compared with 3.7\% reported by Goyache et al. (2003) for field data of the Asturiana de los Valles beef breed in Spain and 4.1\% reported by Morris et al. (1992) in growth selection experiments with Angus and Hereford cattle in New Zealand. However, similar rates of loss of $6.7 \%$ were reported by Patterson et al. (1987) in range beef cattle over a period of 15 years in the United States. Moyo (1990) also reported similar losses to the current study of $6.3 \%$ between birth and 90 days, and 


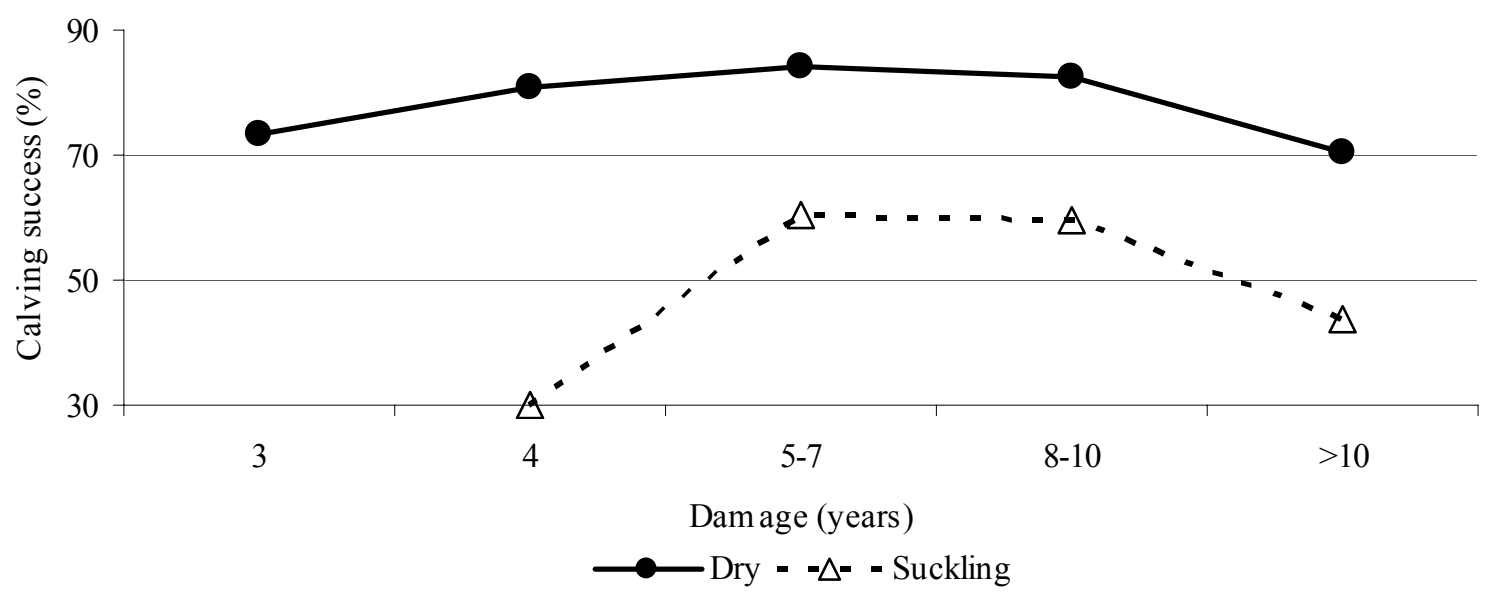

Figure 3 Effect of age of dam and previous lactation status on calving success.

$2.2 \%$ between 90 days and weaning (at 240 days) in a study at Matopos Research Station involving over 5000 calves from a wide range of purebred and crossbred cows evaluated over a period of eight years, while Trail et al. (1977) reported calf losses to one year of age in Afrikaner cattle in Botswana of $8.7 \%$. Prayaga (2004) reported a total pre-weaning loss of $10 \%$ among a range of breeds in a tropical environment in Australia.

The variance ratios for the measures of calf losses were low (Table 4). The direct heritability estimate for STIL was within the range reported in the literature for beef $(0.01$ to 0.15$)$ (Koots et al., 1994, Goyache et al., 2003; Eriksson et al., 2004; Tarrés et al., 2005) and dairy (0.004 - 0.08 in heifers and $0.001-0.12$ in cows) (Weller et al., 1998; Harbers et al., 2000; Meyer et al., 2001). Koots et al. (1994) reported weighted average maternal heritability estimates of 0.15 for both heifers and cows in beef cattle, compared with estimates ranging from 0.002 to 0.02 in dairy cattle (Meyer et al., 2001) and of 0.03 in beef cows (Goyache et al., 2003), in contrast to the apparent lack of variation due to maternal genetic effects in this study. Much lower estimates of repeatability have been reported in the literature for beef ( 0.008 to 0.02 : Goyache et al., 2003) and dairy (0.05 - 0.06: Niskanen \& Juga, 1997). Weller et al. (1988) reported a significant service sire effect in dairy cattle quoting a 0.08 variance ratio. Buddenberg et al. (1990) found that the service sire accounted for a significantly higher amount of variation than sire of dam in Hereford cattle, noting that variance among service sires is a source of phenotypic variance. There are remarkably few genetic studies of calf mortality between birth and weaning. In their study of late calf mortality between birth and weaning expressed as a trait of the dam, Goyache et al. (2003) reported a low direct heritability (0.01) and relatively large ratio $(0.10)$ due to repeated measurements. In contrast to the results in the current study, these authors found the genetic effects on perinatal survival and late mortality to be similar and recommended, on the basis that survival to weaning was an economically important trait, that both be included in a composite trait in beef cattle improvement programmes.

Table 4 Variance ratios (as a proportion of phenotypic variance) for measures of calf survival

\begin{tabular}{lccc}
\hline & \multirow{2}{*}{ Abortions and stillbirths } & \multicolumn{2}{c}{ Calf survival } \\
\cline { 3 - 4 } Heritability & \multirow{2}{*}{$0.15 \pm 0.069$} & $0.02 \pm 0.017$ & Trait of the cow \\
Service sire & - & $0.03 \pm 0.025$ & $0.07 \pm 0.033$ \\
& & & - \\
\hline
\end{tabular}




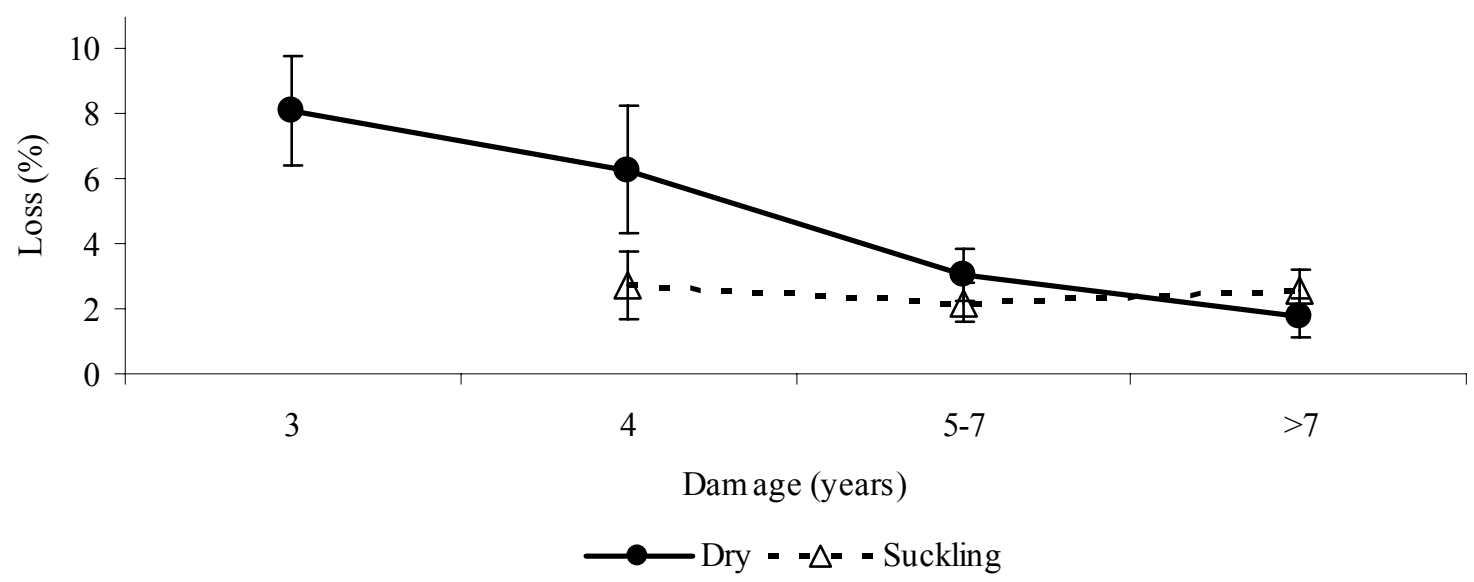

Figure 4 Effects of age of dam and previous lactation status on abortions at term ( $>8$ months) and stillbirths.

Both the effects of year-environment and dam age-PLS were important $(\mathrm{P}<0.01)$ in the analyses of STIL. Heifers had a greater loss compared with older dams of either previous lactation status (Figure 4). Interestingly, four-year old cows, which had not reared a calf to at least 90 days as heifers, also had higher calf losses than older cows. The greater losses in heifers concur with majority of literature reports of perinatal calf losses in both the beef and dairy industry.

Linear and quadratic effects of birth weight were the most important sources of variation for SURV. Mortality was lowest for calves with average birth weights between the mean and two standard deviations above the mean $(32-42 \mathrm{~kg})$ and increased sharply for weights below one standard deviation of the mean $(<27 \mathrm{~kg}$, Figure 5). Similar effects of low birth weight on increased calf mortality were reported by Tomo et al. (2000), where mortality increased by 12 percentage units for Angoni calves less than $18 \mathrm{~kg}$ at birth, while Prayaga (2004) noted higher mortalities for calves with birth weights outside 1.5 to 2 standard deviations of the mean. The effect of sex did not interact with birth weight; however, contrasts indicated mortalities were 1.7 percentage units higher among male calves and concur with the literature (Patterson et al., 1987; Luo et al., 1999; Goyache et al., 2003). In contrast to these results, Hetzel et al. (1989) found that cows that had suckled a calf in the previous season displayed a $10 \%$ increased calf survival rate. The lowest incidence of mortality about the mean birth weight suggests that birth weight is a fitness trait influenced by stabilizing selection towards the mean (Mather, 1973; Falconer \& Mackay, 1996). Analyses of calf loss postcrossover did not reveal any consistent $(\mathrm{P}>0.10)$ line, environment, or line $\mathrm{x}$ environment effects.

Estimated genetic trends for CS and CD were mirror images of each other (Figure 6). Base population (generation 0) estimated breeding values (EBVs) suggest that the average genetic merit of the $\mathrm{S}$ line for both CS and CD was markedly lower than the NS line. The genetic trends for transformed EBVs of CS for the lines differed $(\mathrm{P}<0.05)$ with the $\mathrm{S}$ line showing an improvement of $1.2 \pm 0.14 \%$ /generation $(\mathrm{P}<0.01)$ as against $0.8 \pm 0.13 \% /$ generation $(\mathrm{P}<0.01)$ for the NS line. However there were no line differences for $\mathrm{CD}$ and a favourable genetic trend of $-0.8 \pm 0.09$ days/generation $(\mathrm{P}<0.01)$ for both lines was shown. These results contrast to the absence of significant correlated trends for measures of female fertility in growth selection experiments in cattle (review Mercadante et al., 2003). In a divergent selection experiment for pregnancy rate, Davis et al. (1993) reported a similar genetic trend for pregnancy rate of $0.15 \pm 0.06 \%$ year compared with correlated trends for calving success in the current study of $0.21 \pm 0.022$ and $0.13 \pm 0.022 \% /$ year for the $\mathrm{S}$ and NS lines, respectively.

The correlation of sire solutions (51 sires with more than 10 daughters with mating records) from the analyses of CS with nonlinear and linear models were greater than 0.99 , indicating that while the assumption of normality is clearly violated in the linear analysis, the results from the two methods are essentially the same. Similarly, correlation of sire solutions from the analyses of CS (nonlinear and linear) and CD was 


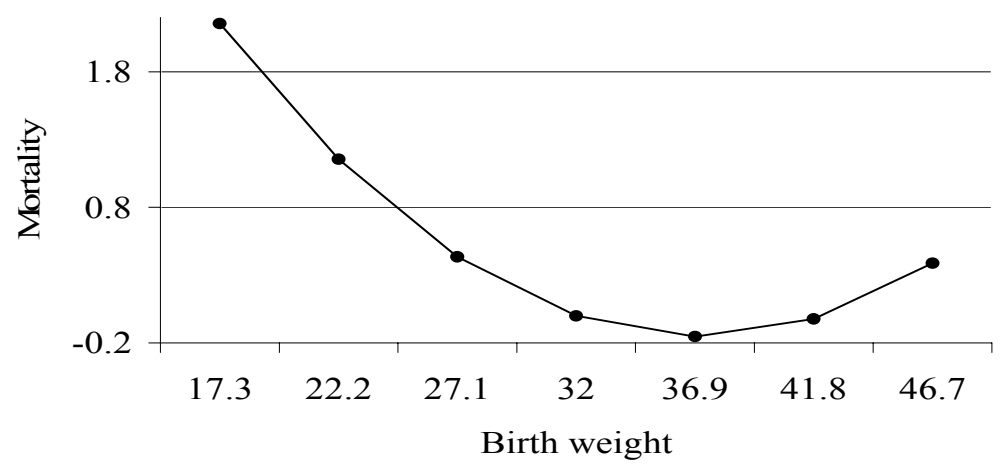

Figure 5 Effect of calf birth weight on calf mortality expressed in units of the underlying scale.

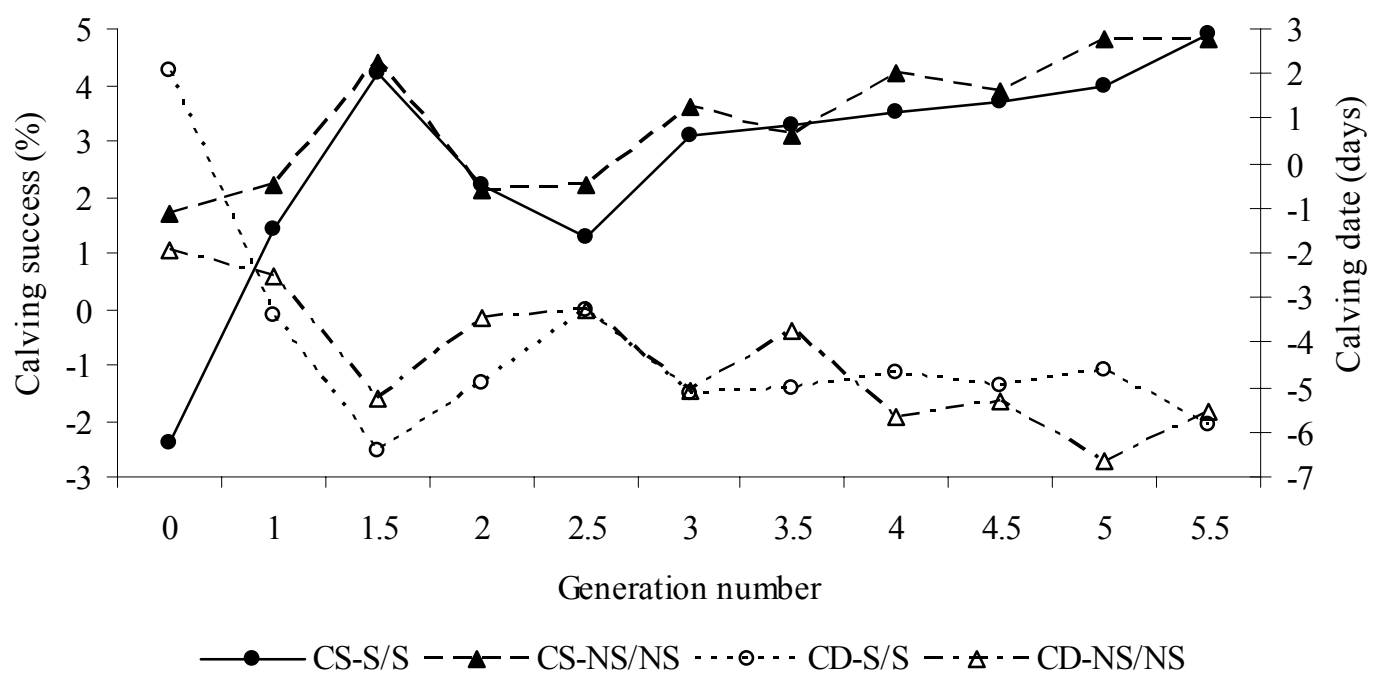

Figure 6 Estimated genetic trends for calving success (CS) and calving date (CD).

-0.90 , while the genetic correlation from the bivariate analysis of CS (linear) and CD was -0.95 indicating that the two traits measure the same genetic variance. However, the major advantage of CD over CS is the higher repeatability estimate. Similar correlations of CS and days to calving EBVs of -0.96 and -0.99 were reported by Johnston et al. (2001) and Donoghue et al. (2004b), but their genetic correlation estimates were lower (-0.66 and -0.73 , respectively). These results indicate that the higher probability of CS is associated with shorter days to calving interval. The regression coefficient for CD EBV was $-1.0 \pm 0.07 \%$ /day, thus a one-day improvement in CD EBV is associated with a $1 \%$ increase in CS EBV (Figure 7). A similar relationship of $-0.6 \%$ /day was reported by Johnston et al. (2001).

The correlations of breeding values of sires (with more than 10 daughters with fertility records) between measures of cow fertility and growth traits (Beffa et al., 2009b) were significantly $(\mathrm{P}<0.10)$ different from zero for the direct genetic breeding values (except for post-weaning gain), but were close to zero with high standard errors for all the maternal genetic breeding values (Table 5). In all cases, the correlations between fertility and direct genetic effects were unfavourable (negative with calving success and positive with calving date). Johnston \& Bunter (1996) also reported generally unfavourable, but nonsignificant correlations, while Mercandante et al. (2003) conclude that selection for body weight does not compromise female fertility for cattle in temperate and tropical climates. 


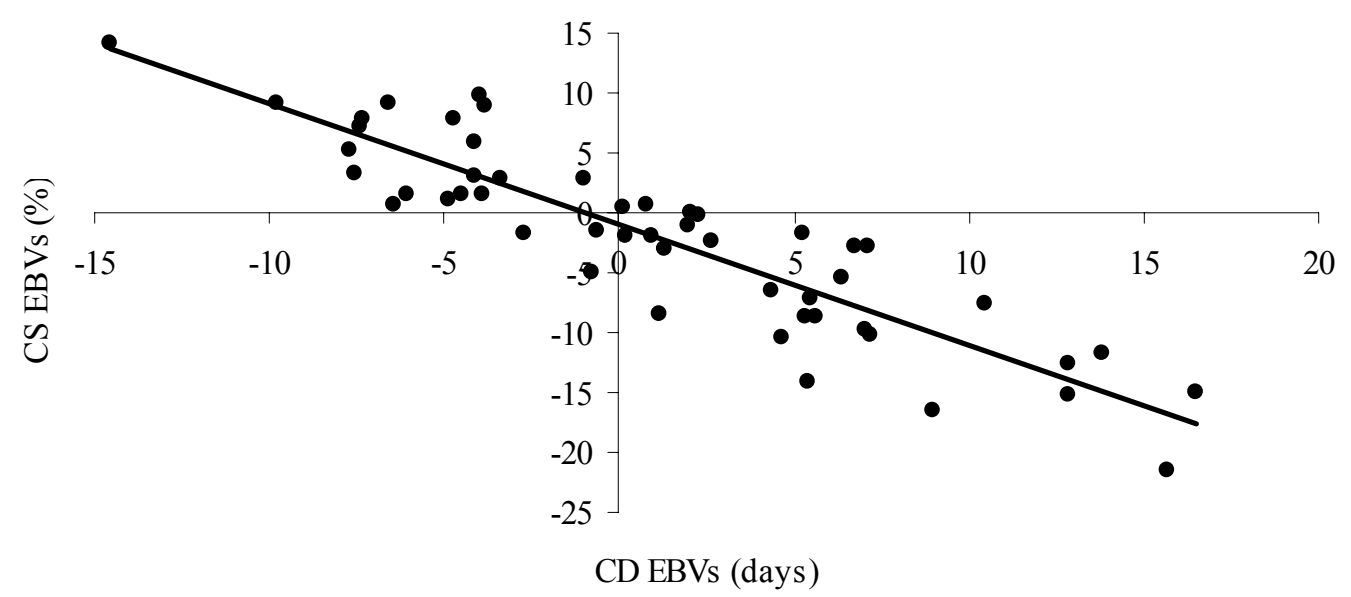

Figure 7 Relationship of estimated breeding values (EBVs) for calving success (CS) and calving date (CD) for 51 sires with more than 10 daughters with fertility records.

Table 5 Correlations (and probability of estimate different to 0 ) of estimated breeding values of sires (with more than 10 daughters with fertility records) between measures of cow fertility and growth traits

\begin{tabular}{lcc}
\hline & Calving success & Calving date \\
\hline Direct: & $-0.17(0.03)$ & $0.26(0.00)$ \\
Birth weight & $-0.18(0.02)$ & $0.28(0.00)$ \\
Weight at 205 days & $-0.14(0.06)$ & $0.21(0.06)$ \\
Weaning weight & $-0.17(0.03)$ & $0.23(0.00)$ \\
12-month weight & $-0.19(0.01)$ & $0.26(0.00)$ \\
18-month weight & $-0.10(0.21)$ & $0.11(0.15)$ \\
Post-weaning daily gain & & \\
Maternal: & $0.05(0.51)$ & $-0.02(0.76)$ \\
Birth weight & $-0.01(0.87)$ & $0.03(0.69)$ \\
Weight at 205 days & $-0.00(0.90)$ & $-0.00(0.97)$ \\
Weaning weight & $0.07(0.35)$ & $0.07(0.34)$ \\
12-month weight & $0.01(0.90)$ & $0.02(0.83)$ \\
18-month weight & $0.14(0.07)$ & $-0.13(0.10)$ \\
Post-weaning daily gain & & \\
\hline
\end{tabular}

\section{Conclusions}

A significant outcome of this study was the manifestation of a large line $\mathrm{x}$ environment interaction for calving success, an overridingly important economic trait, and serves to reinforce the commonly held principle that cattle, and in particular breeding cows, be reared in a similar environment in which selection takes place. Given the low additive genetic variation for measures of reproduction, the low incidence of calving success and the unfavourable genetic correlation with weaning weight (the primary selection trait), it is noteworthy that concomitant genetic improvement for measures of fertility was achieved. Similarly, in spite of the relatively small dataset and the binomial nature of survival traits, some degree of additive genetic variation was expressed for both calf survival at birth and for survival after birth. The results from the 
analyses of fertility and calf survival data in this study support the need to include these measures, together with birth weight and frame size, in routine genetic evaluations, breeding objectives and selection indices. There is also an urgent need to implement data collection strategies to ensure that all calving activities are comprehensively recorded, not least the adequate definition of contemporary groups.

\section{Acknowledgements}

This study formed part of the first author's doctorate thesis who benefited from funding from the John Wakeford Scholarship Trust, the Afrikaner Cattle Society of South Africa, the International Livestock Research Institute the South African National Research Foundation and the Livestock Identification Trust. This work was funded by and carried out at Matopos Research Station, Ministry of Agriculture, Zimbabwe.

\section{References}

Archer, J.A., Arthur, P.F., Parnell, P.F. \& Van de Ven, R.J., 1998. Effect of divergent selection for yearling growth rate on female reproductive performance in Angus cattle. Livest. Prod. Sci. 57, 33-40.

Beffa, L.M., Van Wyk, J.B. \& Erasmus, G.J., 2009a. Long-term selection experiment with Afrikaner cattle. 1. Environmental factors affecting calf growth. S. Afr. J. Anim. Sci. 39, 89-97.

Beffa, L.M., Van Wyk, J.B. \& Erasmus, G.J., 2009b. Long-term selection experiment with Afrikaner cattle. 2. Genetic parameters and genotype $\mathrm{x}$ environment interaction for calf growth traits. S. Afr. J. Anim. Sci. 39, 98-105.

Bellows, R.A., Patterson, D.J., Burfening, P.J. \& Phelps, D.A., 1987. Occurrence of neonatal and postnatal mortality in range beef cattle. II. Factors contributing to calf death. Theriogenology 28, 573-586.

Boldman, K.G., Kriese, L.A., Van Vleck, L.D., Van Tassell, C.P. \& Kachman, S.D., 1995. A Manual for Use of MTDFREML. A set of programs to obtain estimates of variances and covariances [DRAFT]. U.S. Department of Agriculture, Agriculture Research Service.

Buddenberg, B.J., Brown, C.J. \& Brown, A.H., 1990. Heritability estimates of calving date in Hereford cattle maintained on range under natural mating. J. Anim. Sci. 68, 70-74.

Cubas, A.C., Berger, P.J. \& Healey, M.H., 1991. Genetic parameters for calving ease and survival at birth in Angus field data. J. Anim. Sci. 69, 3952-3958.

Davis, G.P., Corbet, N.J, Mackinnon, M.J., Hetzel, D.J.S., Entwistle, K.W. \& Dixon, R., 1993. Response in female fertility and calf growth to selection for pregnancy rate in tropical beef cattle. Aust. J. Agric. Res. 44, 1509-1521.

Dias, L.T., Silva, J.A. II V. \& Albuquerque, L.G.de., 2002. Heritability estimates of pregnancy in Nelore heifers. Proc. $7^{\text {th }}$ World. Congr. Genet. Appl. Livest. Prod. CD Rom communication N ${ }^{\mathrm{o}}$. 08-40.

Donoghue, K.A., Rekaya, R. \& Bertrand, J.K., 2004a. Comparison of methods for handling censored records in beef fertility data, field data. J. Anim. Sci. 82, 357-361.

Donoghue, K.A., Rekaya, R., Bertrand, J.K. \& Misztal, I., 2004b. Threshold-linear analysis of measures of fertility in artificial insemination data and days to calving in beef cattle. J. Anim. Sci. 82, 987-993.

Doyle, S.P., Golden, B.L., Green, R.D. \& Brinks, J.S., 2000. Additive genetic parameter estimates for heifer pregnancy and subsequent reproduction in Angus females. J. Anim. Sci. 78, 2091-2098.

Eriksson, S., Näsholm, A., Johansson, K. \& Philipsson, J., 2004. Genetic parameters for calving difficulty, stillbirth, and birth weight for Hereford and Charolais at first and later parities. J. Anim. Sci. 82, 375-383.

Evans, J.L., Golden, B.L., Bourdon, R.M. \& Long, K.L., 1999. Additive genetic relationships between heifer pregnancy and scrotal circumference in Hereford cattle. J. Anim. Sci. 77, 2621-2628.

Falconer, D.S., 1990. Selection in different environments, effects on environmental sensitivity (reaction norm) and on mean performance. Genet . Res. 56, 57-70.

Falconer, D.S. \& Mackay, T.F.C., 1996. Introduction to Quantitative Genetics. $3^{\text {rd }}$ ed., Longman, Essex, UK.

Frisch, J.E., 1989. Studies on growth and reproduction of cattle in the tropics. Proc. Final Co-ord. Mtg. Use Nuclear Tech. Impr. Domestic Buffalo Prod. Asia - Phase II, 20-24 February 1989, Rockhampton, Australia. International Atomic Energy Agency, Vienna, Austria. pp. 91-102.

Gilmour, A.R., Gogel, B.J., Cullis, B.R., Welham, S.J. \& Thompson, R., 2002. ASReml User Guide Release 1.0 VSN International Ltd, Hemel Hempstead, HP1 1ES, UK. 
Goyache, F., Gutiérrez, J.P., Alvarez, I., Fernández, I., Royo, L.J. \& Gómez, E., 2003. Genetic analysis of calf survival at different preweaning ages in beef cattle. Livest. Prod. Sci. 83, 13-20.

Gutiérrez, J.P., Alvarez, I., Fernández, I., Royo, L.J., Díez, J. \& Goyache, F., 2002. Genetic relationships between calving date, calving interval, age at first calving and type traits in beef cattle. Livest. Prod. Sci. 78, 215-222.

Harbers, A., Segeren, L. \& De Jong, G., 2000. Genetic parameters for stillbirth in the Netherlands. Interbull Bulletin 25, 117-122.

Harwin, G.O., Lamb, R.D. \& Bisschop, J.H.R., 1967. Some factors affecting reproductive performance of beef females. Proc. S. Afr. Soc. Anim. Prod. 6, 171-177.

Hetzel, D.J.S., Goddard, M.E, Aspden, W.J. \& Dixon, R., 1985. Genetic and environmental trends for pregnancy rate in a herd of Droughtmaster cattle in northern Australia. Proc. Aust. Assoc. Anim. Breed. Genet. 5, 165-166.

Hetzel, D.J.S., Mackinnon, M.J., Dixon, R. \& Entwistle, K.W., 1989. Fertility in a tropical beef herd divergently selected for pregnancy rate. Anim. Prod. 49, 73-81.

Holness, D.H., Hale, D.H. \& Hopley, J.D.H., 1980. Ovarian activity and conception during the post-partum period in Afrikaner and Mashona cows. Zimbabwe J. Agric. Res. 18, 3-11.

Jinks, J.L. \& Connolly, V., 1973. Selection for specific and general response to environmental differences. Heredity 30, 33-40.

Johnston, D.J. \& Bunter, K.L., 1996. Days to calving in Angus cattle: genetic and environmental effects, and covariances with other traits. Livest. Prod. Sci. 45, 13-22.

Johnston, D.J., Henshall, J.M. \& Tier, B., 2001. Estimate of the genetic correlation between calving success and days to calving in Angus females. Proc. Assoc. Advmt. Anim. Breed. Genet. 14, 353-356.

Johnson, M.H. \& Notter, D.R., 1987. Simulation of genetic control of reproduction in beef cows. II. Derived genetic parameters. J. Anim. Sci. 65, 76-87.

Kadarmideen, H.N. \& Wegmann, S., 2003. Genetic relationship among body condition score, type, fertility and production traits in Swiss Holstein cattle. Proc. Assoc. Advmnt. Anim. Breed. Genet. 15, 77-81.

Koots, K.R., Gibson, J.P., Smith, C. \& Wilton, J.W., 1994. Analyses of published genetic parameter estimates for beef production traits. 1. Heritability. Anim. Breed. Abstr. 62, 309-338.

Luo, M.F., Boettcher, P.J., Dekkers, J.C.M. \& Schaeffer, L.R., 1999. Bayesian analysis for estimation of genetic parameters of calving ease and stillbirth for Canadian Holsteins. J. Dairy. Sci. 82, 1848-1858.

Lush, J.L., Lamoreux, W.F. \& Hazel, L.N., 1948. The heritability of resistance to death in the fowl. Poult. Sci. 27, 375-388.

Mather, K., 1973. Genetical Structure of Populations. Chapman \& Hall, London, UK.

Mercadante, M.E.Z., Packer, I.U., Razook, A.G., Cyrillo, J.N.S.G. \& Figueiredo, L.A., 2003. Direct and correlated responses to selection for yearling weight on reproductive performance of Nelore cows. J. Anim. Sci. 2003, 376-384.

Meyer, K. \& Hill, W.G., 1992. Approximation of sampling variances and confidence intervals for maximum likelihood estimates of variance components. J. Anim. Breed. Genet. 109, 264-280.

Meyer, K. \& Johnston, D.J., 2003. Estimates of genetic correlations between live ultrasound scan traits and days to calving in Hereford cattle. Proc. Assoc. Advmt. Anim. Breed. Genet. 15, 387-390.

Meyer, C.L., Berger, P.J., Thompson, J.R. \& Sattler, C.G., 2001. Genetic evaluation of Holstein sires and maternal grandsires in the United States for perinatal survival. J. Dairy Sci. 84, 1246-1254.

Morris, C.A., Baker, R.L. \& Hunter, J.C., 1992. Correlated responses to selection for yearling or 18-month weight in Angus and Hereford cattle. Livest. Prod. Sci. 30, 33-52.

Morris, C.A., Wilson, J.A., Bennett, G.L., Cullen, N.G., Hickey, S.M. \& Hunter, J.C., 2000. Genetic parameters for growth, puberty, and beef cow reproductive traits in a puberty selection experiment. $\mathrm{N}$. Z. J. Agric. Res. 43, 83-91.

Moyo, S., 1990. Evaluation of the productivity of indigenous cattle and some exotic beef breeds and their crosses in Zimbabwe. International Livestock Centre for Africa, Addis Ababa, Ethiopia.

Neter, J., Wasserman, W. \& Kutner, M.M., 1983. Applied Linear Regression Models. Irwin, Illinois

Newman, S., Morris, C.A., Baker, R.L. \& Nicoll, G.B., 1992. Genetic improvement of beef cattle in New Zealand: breeding objectives. Livest. Prod. Sci. 32, 111-130. 
Niskanen, S. \& Juga, J., 1997. Calving difficulties and calf mortality in Finnish dairy cattle population. Interbull Bulletin 18, 17-20.

Patterson, D.J., Bellows, R.A., Burfening, P.J. \& Carr, J.B., 1987. Occurrence of neonatal and postnatal mortality in range beef cattle. I. Calf loss incidence from birth to weaning, backward and breech presentations and effects of calf loss on subsequent pregnancy rate of dams. Theriogenology 28 , 557-551.

Philipsson, J., 1996. Strategies to reduce problems in calving performance and stillbirths by selection and differential use of bulls. Interbull Bulletin 12, 65-71.

Ponzoni, R.W., 1992. Which trait for genetic improvement of beef cattle reproduction: calving rate or calving day? J. Anim. Breed. Genet. 109, 119-128.

Prayaga, K.C., 2004. Evaluation of beef cattle genotypes and estimation of direct and maternal genetic effects in a tropical environment. 3. Fertility and calf survival traits. Aust. J. Agric. Res. 55, 811-824.

Rakha, A.M., Igboeli, G. \& King, I.L., 1971. Calving interval, gestation and postpartum periods of indigenous Central African cattle under a restricted system of breeding. J. Anim. Sci. 32, 507-509.

Rust, T. \& Groeneveld, E., 2001. Variance component estimation on female fertility traits in beef cattle. (Review). S. Afr. J. Anim. Sci. 31, 131-141.

Rust, T. \& Groeneveld, E., 2002. Variance component estimation of female fertility traits in two indigenous and two European beef cattle breeds of South Africa. S. Afr. J. Anim. Sci. 32, 23-29.

Tarrés, J., Casellas, J. \& Piedrafita, J., 2005. Genetic and environmental factors influencing mortality up to weaning of Bruna dels Pirineus beef calves in mountain areas. A survival analysis. J. Anim. Sci. 83, 543-551.

Tomo, P.S.M., Tawah, C.L., Swanepoel, F.J.C. \& Hoogenboezem, J.M., 2000. Production characteristics of Angoni cattle in Mozambique: 2. Non-genetic influences on fertility, survivability and productivity. Trop. Sci. 40, 3-10.

Trail, J.C.M., Buck, N.G., Light, D., Rennie, T.W., Rutherford, A., Miller, M., Pratchett, D. \& Capper, B.S., 1977. Productivity of Africander, Tswana, Tuli and crossbred beef cattle in Botswana. Anim. Prod. 24, 57-62.

Weller, J.I., Misztal, I. \& Gianola, D., 1988. Genetic analysis of dystocia and calf mortality in IsraeliHolsteins by threshold and linear model. J. Dairy Sci. 71, 2491-2501. 